\title{
Prefatory Note <1953>
}

This publication contains the text of the fully elaborated ${ }^{1}$ lecture course that was held under the same title in the summer semester of 1935 at the University of Freiburg im Breisgau.

What was spoken no longer speaks in what is printed.

As an aid to the reader, without any change in content, longer sentences have been broken up, the continuous text has been more fully articulated into sections, repetitions have been deleted, oversights eliminated, and imprecisions clarified.

Whatever stands between parentheses was written during the elaboration of the lectures. Whatever is set within brackets consists of remarks inserted in subsequent years. ${ }^{2}$

I. By vollständig ausgearbeitete, Heidegger probably means that he finished writing the text in 1935, with the exception of the changes he notes below. (All footnotes are by the translators, with the exception of two notes by Heidegger that we will mark as such.)

2. The 1953 edition often did not follow the conventions Heidegger describes here: later insertions of several sentences were usually printed in 
In order properly to consider in what sense and on what grounds the term "metaphysics" is included in the title, the reader must first have taken part in completing the course of the lectures.

brackets, but shorter ones were usually printed in parentheses. The Gesamtausgabe and the more recent Niemeyer editions use brackets for all the later insertions. We will observe the usage of these recent editions, while noting all occasions where parentheses in the 1953 edition have been revised to brackets. Translators' interpolations and references to the original German are printed in angle brackets: <>. 